\title{
Optimasi Algoritma K-Means Clustering dengan Parallel Processing menggunakan Framework $R$
}

\author{
Mastura Diana Marieska ${ }^{1}$, Suci Lestari ${ }^{2}$, Calvin Mahendra ${ }^{3}$, Nabila Rizky Oktadini ${ }^{4}$, Muhammad Ali Buchari ${ }^{5}$ \\ Distributed System Research Group, Fakultas Ilmu Komputer, Universitas Sriwijaya \\ Jalan Palembang Prabumulih KM 32 Palembang Sumatera Selatan \\ ${ }^{1}$ mastura.dianalilkom.unsri.ac.id \\ 209021281722038 estudents.unsri.ac.id \\ ${ }^{3} 09021381722115$ estudents.unsri.ac.id \\ ${ }^{4}$ nabila@unsri.ac.id \\ ${ }^{5}$ ali bucharieilkom.unsri.ac.id
}

\begin{abstract}
Abstrak-Parallel processing sering digunakan untuk melakukan optimasi execution time terhadap algoritma data mining. Pada penelitian ini, parallel processing digunakan untuk melakukan optimasi pada algoritma clustering $\mathbf{K}$ Means. Implementasi algoritma K-means dilakukan dengan memanfaatkan package yang tersedia pada framework $R$. Algoritma K-Means dijalankan secara serial dan parallel. Untuk mendapatkan persentase optimasi, maka dilakukan perbandingan antara execution time pada parallel processing dan execution time pada serial processing. Penelitian ini menggunakan dataset Boston Housing yang umum digunakan pada data mining. Skenario pengujian dibedakan berdasarkan jumlah core dan jumlah centroid. Hasil pengujian menunjukkan bahwa parallel processing untuk tiap skenario memiliki execution time yang lebih kecil daripada serial processing. Optimasi yang dihasilkan cukup signifikan, yakni bernilai $20 \%$ hingga $52 \%$. Optimasi tertinggi didapatkan pada jumlah core terbanyak dan jumlah centroid terbesar.
\end{abstract}

Kata kunci- Parallel Processing, Clustering, K-means, Framework R, Execution Time

\section{Pendahuluan}

Teknik parallel processing berkembang pesat seiring dengan berkembangnya teknologi multicore processor. Dengan adanya lebih dari satu core pada prosesor, maka prosesor dapat menjalankan lebih dari satu proses yang terpisah pada waktu bersamaan [1]. Hal ini meningkatkan performansi prosesor secara signifikan. Tidak perlu hardware khusus untuk mengimplementasikan strategi paralel karena hampir semua komputer modern telah memiliki lebih dari satu prosesor.

Dukungan hardware saja tidak cukup untuk dapat mengembangkan strategi paralel dengan baik. Diperlukan juga dukungan software. Beberapa bahasa pemrograman telah memiliki kemampuan paralel. Salah satu framework yang mendukung implementasi paralel adalah R. R merupakan framework untuk data analytics yang memudahkan programmer dalam data manipulation, perhitungan data, dan graphical display [2]. R dilengkapi dengan banyak library untuk analisis data yang dikembangkan secara open source.

Mengembangkan solusi paralel tidaklah mudah. Menambah core pada prosesor tidak serta merta membuat program berjalan lebih cepat [3]. Programmer perlu mengidentifikasi apakah suatu algoritma data mining berpotensi untuk dioptimasi dengan parallel processing. Salah satu indikasi algoritma dapat dioptimalkan dengan parallel processing adalah sedikitnya dependency antar data yang diproses secara bersamaan [4]. Apabila suatu algoritma memiliki tingkat keterkaitan yang tinggi maka pemrosesan terhadap data yang terkait tersebut perlu dilakukan secara serial.

Pada penelitian ini, parallel processing digunakan untuk melakukan optimasi terhadap algoritma K-Means. Algoritma K-Means merupakan algoritma untuk mengelompokkan sejumlah node menjadi beberapa cluster. Pengelompokan ini dilakukan dengan cara menghitung jarak antara node dengan pusat dari tiap cluster. Tiap node dikelompokkan pada cluster yang memiliki jarak terdekat. Pada K-Means, proses untuk mencari jarak pada masingmasing node dapat dilakukan terpisah. Tidak ada keterkaitan antar data dalam menghitung jarak. Proses pada tiap node dapat dilakukan secara bersamaan, sehingga dapat disimpulkan bahwa algoritma K-Means cocok untuk diimplementasikan secara paralel.

Dataset yang digunakan pada penelitian ini adalah data Boston Housing, yaitu data mengenai housing market di kota Boston, Amerika Serikat yang dikumpulkan oleh Statlib Library of Carnegie Mellon University [5]. Dataset ini sering dipakai pada penelitian mengenai data mining seperti pada penelitian prediksi housing prices [6] dan regression [7]. Algoritma K-Means diimplementasikan pada framework R menggunakan library. Dataset Boston Housing akan menjadi input pada program $\mathrm{R}$ untuk kemudian diproses menggunakan algoritma K-Means. 
Untuk mengamati seberapa besar pengaruh parallel processing, maka pada penelitian ini akan dilakukan pula pemrosesan data dengan serial/sequential processing. Execution time pada serial processing akan digunakan sebagai nilai dasar (base). Execution time pada parallel processing akan dihitung berdasarkan jumlah core yang digunakan, yaitu 2, 3, dan 4 core. Dengan membandingkan execution time pada serial processing dengan parallel processing maka dapat dianalisis seberapa banyak optimasi yang dihasilkan oleh parallel processing.

Telah banyak penelitian yang dilakukan untuk membandingkan execution time antara serial processing dengan parallel processing. Pada penelitian [8], dilakukan perbandingan execution time antara serial dan paralel dalam kasus stemming bahasa Indonesia. Hasilnya, solusi paralel berhasil mengurangi execution time hingga $98,45 \%$. Penelitian [9] mengenai multicore parallel pada geospatial visualizations menghasilkan kesimpulan bahwa parallel processing lebih cepat sampai dengan $4 \mathrm{x}$ daripada serial processing

Parallel processing tidak selalu menghasilkan performansi yang lebih baik daripada serialnya. Seperti pada penelitian [10], solusi paralel dengan Graphical Proessing Unit (GPU) menghasilkan execution time yang lebih besar daripada serial processing pada CPU. Sehingga disimpulkan untuk jumlah data yang relatif kecil sebaiknya menggunakan serial processing pada CPU. Pada penelitian [11] dilakukan survey teoritis mengenai variasi parallel package yang tersedia pada $\mathrm{R}$ di tahun 2014. Penelitian mengenai implementasi paralel menggunakan framework $\mathrm{R}$ juga telah banyak dilakukan. Penelitan [12] menggunakan parallel processing pada $\mathrm{R}$ untuk regression task. Solusi paralel dengan package pada $\mathrm{R}$ berhasil memperoleh execution time terkecil.

Berdasarkan analisis terhadap penelitian terkait, dapat dibuat hipotesis bahwa secara umum parallel processing dapat memperkecil execution time. Namun terdapat kasus tertentu dimana serial processing lebih cepat daripada parallel processing. Penelitian ini bertujuan untuk melakukan optimasi execution time terhadap algoritma clustering K-means. Selain itu, akan dihitung seberapa besar optimasi yang dihasilkan jika dibandingkan dengan serial processing.

\section{METOde PENELITIAN}

Pada penelitian ini dilakukan implementasi algoritma KMeans pada framework $\mathrm{R}$ dengan memanfaatkan package terkait data mining dan multicore parallel. Tersedianya multicore processor pada hardware yang digunakan memungkinkan pemrosesan data dilakukan secara bersamaan pada tiap core. Telah dilakukan analisis terhadap dataset dan library yang tepat untuk dipakai penelitian ini.

\section{A. Parallel Processing}

Sebuah prosesor merupakan inti dari tiap komputer. Komputer klasik memiliki hanya satu prosesor dengan 1 core di dalamnya. Seiring berkembangnya teknologi prosesor, prosesor masa kini dapat memiliki lebih dari satu core, atau yang disebut dengan multicore. Penambahan core ini menjadikan komputer mampu melakukan lebih dari 1 task dalam waktu yang sama. Dengan demikian performansi dari komputer dapat meningkat Suatu komputer yang memiliki satu prosesor yang terdiri atas 4 core dapat melakukan 4 komputasi dalam waktu bersamaan. Keempat core tersebut terkoneksi dengan main memory yang sama. Berikut ilustrasi struktur prosesor dan core.

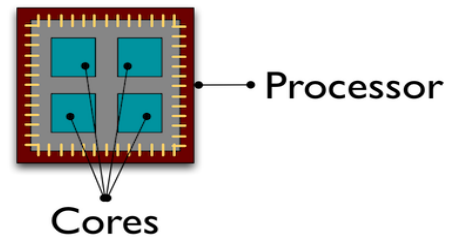

Gambar. 1 Multicore processor [13]

Thread adalah lightweight process, yaitu bagian dari proses yang memiliki creation cost yang lebih ringan dan tidak memiliki alokasi memori sendiri [14]. Pada pemrosesan serial, suatu thread dapat dieksekusi setelah thread sebelumnya selesai dijalankan dan telah memperoleh hasil (return). Konsep dasar dari implementasi paralel yang membedakan dengan implementasi secara serial adalah thread pada paralel dapat dijalankan secara bersamaan pada satu waktu. Oleh karena itu, data yang digunakan pada tiap thread harus tidak saling berkaitan satu sama lain sehingga dapat diproses secara terpisah. Apabila data yang digunakan merupakan output dari proses sebelumnya maka kedua proses ini tidak dapat dijalankan secara paralel. Berikut adalah ilustrasi pemrosesan serial menggunakan 1 core dan paralel menggunakan 4 core.

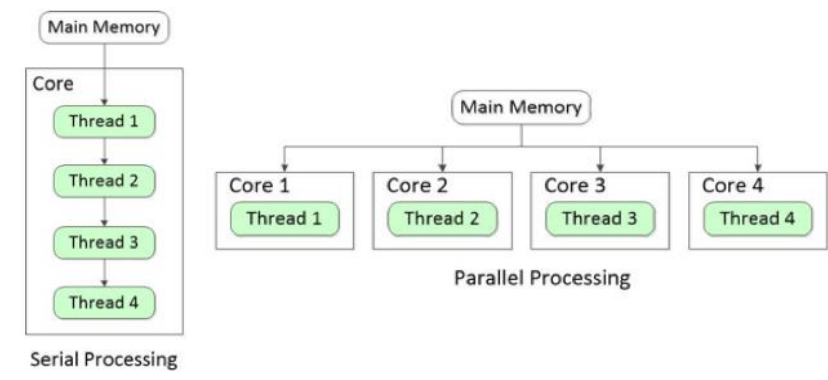

Gambar. 2 Skema serial processing dan parallel processing

\section{B. K-Means Clustering}

Data clustering merupakan teknik pengelompokan data ke dalam cluster, sedemikian sehingga data pada satu cluster memiliki kemiripan yang lebih tinggi dibanding data pada cluster lain [15]. K-Means merupakan salah satu metode data clustering non hirarki yang mempartisi data ke cluster yang bersesuaian [16]. Metode ini mempartisi data ke dalam cluster sehingga data yang memiliki karakteristik yang sama dikelompokkan ke dalam satu cluster yang sama dan data yang mempunyai karakteristik yang berbeda dikelompokkan ke dalam cluster yang lain. 
Alur proses $K$-Means clustering dapat dilihat pada Gambar 3.

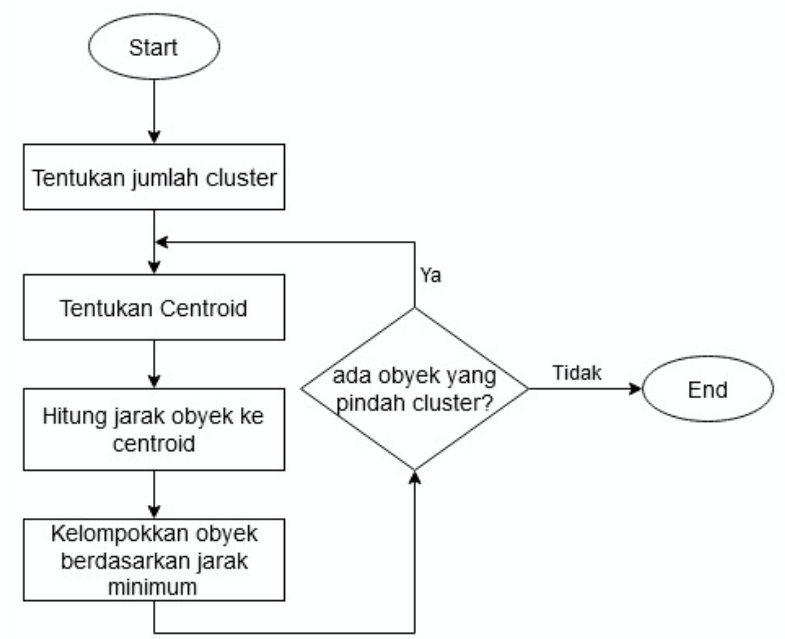

Gambar. 3 Alur proses k-means [16]

Pada penelitian ini digunakan dataset Boston Housing sebagai data yang akan diproses dengan algoritma KMeans. Dataset Boston Housing disediakan oleh perpustakaan StatLib yang dikelola oleh Universitas Carnegie Mellon. Dataset ini dibuat pada tahun 1993 dan telah menjadi dataset well known di kalangan peneliti [5] Data harga rumah di wilayah Boston terdiri atas 14 fitur, yaitu 13 variabel input dan 1 variabel output. Terdapat 506 baris data yang dikumpulkan oleh U.S Census Service terkait kebutuhan perumahan saat itu [6]. Dimensi dari dataset ini adalah 506x14.

\section{Framework dan Library}

$\mathrm{R}$ adalah bahasa pemrograman dan framework untuk data analytics. Bahasa $\mathrm{R}$ merupakan pengembangan dari bahasa $S$ yang dikembangkan di AT\&T Bell Laboratories oleh Rick Becker, John Chambers dan Allan Wilks [2]. R merupakan framework yang dapat dijalankan pada berbagai arsiektur komputer, seperti Intel, PowerPC, Alpha, dan Sparc. Pengembangan $\mathrm{R}$ saat ini dilakukan oleh core team yang terdiri dari sejumlah orang dari berbagai institusi di seluruh dunia [17]. Framework R juga dilengkapi GUI yang memudahkan pengguna untuk membuat, menjalankan, dan plot grafik. Salah satu framework $\mathrm{R}$ yang dilengkapi dengan GUI adalah RStudio.

Keunggulan dari framework $\mathrm{R}$ adalah tersedianya banyak library yang dikembangkan oleh komunitas di seluruh dunia. Library ini berbentuk package yang bersifat free dan open source. Library tersedia pada repository $\mathrm{R}$ yaitu CRAN. CRAN memiliki banyak mirror server di berbagai universitas dunia. Saat ini tersedia 16.385 packages pada $\mathrm{R}$. Package pada $\mathrm{R}$ dapat berupa penambahan fitur, implementasi algoritma data analytics, maupun fitur pembuatan grafik dan visualisasi. Diperlukan eksplorasi dan analisis untuk menentukan package yang tepat untuk digunakan pada suatu penelitian. Pada penelitian ini digunakan package untuk implementasi parallel processing, implementasi data clustering menggunakan K-Means, dan pengaksesan dataset Boston Housing.

1) Library parallel: diperkenalkan oleh Luke Tierney dan tim R-Core untuk mendukung komputasi parallel di R. Versi pertama dari library ini disertakan dalam $\mathrm{R}$ versi 2.14.0 dan telah menjadi bagian dari inti dalam package $\mathrm{R}$ sejak saat itu [18]. Library parallel menggunakan coarse-grained parallelization menggunakan fork thread pada sistem operasi. Terdapat 3 method pada pada library parallel yang digunakan di penelitian ini, yaitu detectCores(), lapply(), dan mclapply().

- detectCores() berfungsi untuk mendapatkan jumlah core dalam prosesor. Method ini mengembalikan nilai angka jumlah core yang terdeteksi. Berikut kode program untuk mendapatkan jumlah core dan ditampung pada variable numcores.

$>$ numCores <- detectCores()

- lapply () berfungsi untuk melakukan operasi pada objek list dan mengembalikan objek list dengan panjang yang sama. Method ini mengembalikan list hasil eksekusi fungsi input. Berikut kode program untuk menjalankan lapply() dan menampung hasilnya pada variabel res.

\begin{tabular}{l}
\hline$>$ res $<-$ lapply (data, fx) \\
Argumen : \\
data $\quad$ : Vektor atau objek yang ingin diolah \\
fx $\quad$ : Fungsi diterapkan ke tiap elemen data
\end{tabular}

- mclapply() untuk menjalankan komputasi paralel pada mesin dengan beberapa core atau CPU. Dengan fungsi ini, tugas dapat dibagikan pada seluruh core secara merata sehingga bisa berjalan bersamaan. Method mclapply() merupakan versi paralel dari lapply (), yang mengembalikan list dengan panjang yang sama dengan list masukan. Berbeda dgn lapply(), pada mclapply() terdapat argumen tambahan yaitu jumlah core yang ingin digunakan. Berikut kode program untuk menjalankan mclapply () dan menampung hasilnya pada variabel res.

$>$ res<-mclapply (data, fx, mc.cores=4)

Argumen :

data : Vektor atau objek yang ingin diolah

fx : Fungsi diterapkan ke tiap elemen data

mc.cores: Jumlah cores yang digunakan

2) Library MASS: dikembangkan oleh Venables dan Ripley sebagai materi suplemen dari buku mereka yang berjudul "Modern Applied Statistics with S" (4th edition, 2002) [19]. Library MASS berisi fungsi dan dataset yang digunakan sebagai contoh dan latihan pada buku tersebut, salah satunya adalah dataset Boston Housing. Berikut adalah contoh penggunaan dataset Boston Housing yang menjadi salah satu parameter masukan pada suatu fungsi: 
kmeans (Boston, 5, nstart=nstart)

\section{HASIL DAN PEMBAHASAN}

Perbandingan execution time dilakukan terhadap serial processing dengan parallel processing dalam menjalankan algoritma K-Means untuk dataset Boston Housing. Algoritma K-Means dipilih karena dalam pencarian jarak antar node tidak ada keterkaitan data, sehingga dapat dilakukan pemrosesan secara terpisah. Data Boston Housing digunakan pada penelitian ini karena mudah didapat dan merupakan contoh dataset yang umum digunakan untuk penelitian di bidang data mining. Implementasi kedua program, baik serial maupun paralel dilakukan menggunakan bahasa $\mathrm{R}$ dengan menggunakan aplikasi RStudio. Kedua progam akan dijalankan pada komputer yang memiliki multicore processor. Tabel I merupakan spesifikasi hardware dan software dari komputer yang digunakan.

TABEL I

SPESIFIKASI HARDWARE DAN SOFTWARE

\begin{tabular}{|l|l|l|}
\hline No & Hardware/Software & Spesifikasi \\
\hline 1 & Processor & $\begin{array}{l}\text { Intel(R) Core(TM) i5- } \\
5200 \mathrm{U}\end{array}$ \\
\hline 2 & Jumlah core pada processor & 4 \\
\hline 3 & RAM & 4 GB \\
\hline 4 & Sistem Operasi & Ubuntu 20.04 \\
\hline 5 & RStudio & 1.3 .1073 \\
\hline
\end{tabular}

Agar dapat melalukan pengukuran execution time, dibuatlah sebuah proram uji yang menggunakan library parallel dan MASS. Pada program uji ini diimplementasikan suatu fungsi yang memanggil method kmeans () dengan masukan berupa dataset Boston Housing. Pencatatan execution time dilakukan dengan memakai fitur dasar R yaitu system.time yang menghitung berapa lama suatu fungsi dijalankan dalam satuan detik. Berikut adalah kode program uji menggunakan bahasa $\mathrm{R}$.

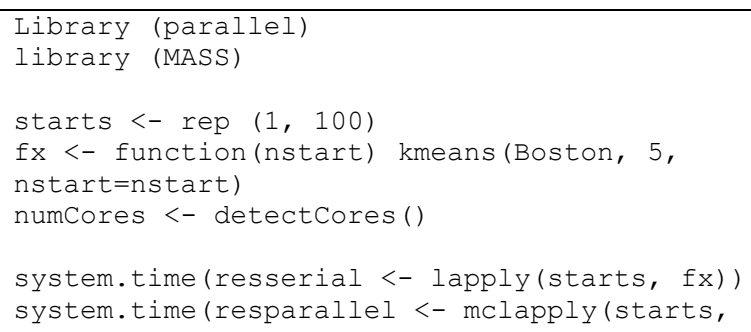

Skenario pengujian dibedakan berdasarkan jumlah centroid untuk melihat keterkaitan jumlah centroid dengan optimasi paralel yang dihasilkan. Jumlah centroid yang digunakan adalah 10, 50, 100, 150, 200, dan 250. Dalam menjalankan suatu program, terdapat kemungkinan program tersebut akan diinterupsi oleh sistem operasi jika terdapat task lain dengan prioritas yang lebih tinggi. Untuk itu perhitungan execution time dilakukan sebanyak 5 kali dan dihitung nilai rata-ratanya/ mean. Gambar 4 adalah alur pengujian untuk membandingkan execution time serial processing dengan parallel processing.

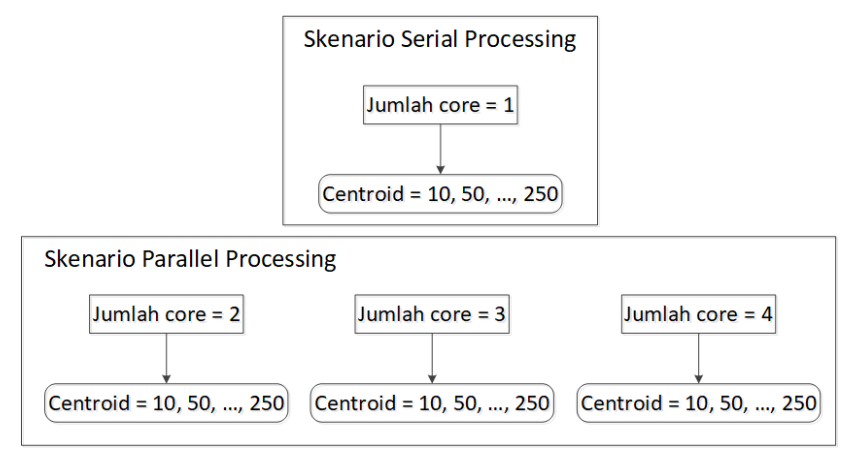

Gambar. 4 Skenario pengujian

Skenario uji yang pertama adalah serial processing untuk 6 jenis centroid. Serial processing dijalankan hanya pada satu core dengan menggunakan method lapply(). Execution time diukur dalam satuan detik. Berikut adalah execution time untuk serial processing dengan $\mathrm{n}$ adalah jumlah centroid.

TABEL II

SKENARIO SERIAL PROCESSING

\begin{tabular}{|c|c|c|c|c|c|c|}
\hline \multirow{2}{*}{$\mathbf{n}$} & \multicolumn{5}{|c|}{ Percobaan ke } & \multirow{2}{*}{ Mean } \\
\cline { 2 - 6 } & $\mathbf{1}$ & $\mathbf{2}$ & $\mathbf{3}$ & $\mathbf{4}$ & $\mathbf{5}$ & \\
\hline 10 & 0,123 & 0,119 & 0,114 & 0,119 & 0,119 & 0,119 \\
\hline 50 & 0,275 & 0,273 & 0,277 & 0,270 & 0,266 & 0,272 \\
\hline 100 & 0,426 & 0,423 & 0,419 & 0,418 & 0,435 & 0,424 \\
\hline 150 & 0,537 & 0,542 & 0,537 & 0,541 & 0,550 & 0,541 \\
\hline 200 & 0,631 & 0,632 & 0,641 & 0,625 & 0,648 & 0,635 \\
\hline 250 & 0,686 & 0,694 & 0,686 & 0,678 & 0,681 & 0,685 \\
\hline
\end{tabular}

Dari hasil pengujian pada serial processing, dapat dilihat bahwa semakin bertambahnya jumlah centroid, maka bertambah pula execution time. Hal ini sesuai dengan logika dari algoritma K-Means, bahwa semakin banyak jumlah centroid maka semakin banyak jarak antar node yang harus dihitung. Selisih antar percobaan tidak terlalu besar. Misalnya pada jumlah centroid 50, selisih execution time terbesar adalah 11 milisecond. Dapat dikatakan bahwa method lapply () dijalankan secara konsisten karena tidak terdapat lonjakan execution time.

Setelah didapatkan nilai execution time untuk serial processing sebagai dasar perbandingan, maka selanjutnya dijalankan scenario uji untuk parallel processing. Parallel processing dijalankan menggunakan method mclapply() pada jumlah core yang berbeda-beda, yaitu 2, 3, dan 4 core.

TABEL III

SKenario PARALLEL PROCESSING 2 CORE

\begin{tabular}{|c|c|c|c|c|c|c|}
\hline \multirow{2}{*}{$\mathbf{n}$} & \multicolumn{5}{|c|}{ Percobaan ke } & \multirow{2}{*}{ Mean } \\
\cline { 2 - 6 } & $\mathbf{1}$ & $\mathbf{2}$ & $\mathbf{3}$ & $\mathbf{4}$ & $\mathbf{5}$ & \\
\hline 10 & 0,097 & 0,096 & 0,093 & 0,095 & 0,093 & 0,095 \\
\hline 50 & 0,188 & 0,190 & 0,188 & 0,186 & 0,186 & 0,188 \\
\hline 100 & 0,268 & 0,266 & 0,269 & 0,272 & 0,273 & 0,270 \\
\hline 150 & 0,341 & 0,345 & 0,346 & 0,338 & 0,342 & 0,342 \\
\hline 200 & 0,396 & 0,394 & 0,401 & 0,391 & 0,398 & 0,396 \\
\hline 250 & 0,435 & 0,432 & 0,433 & 0,434 & 0,431 & 0,433 \\
\hline
\end{tabular}


Jika dibandingkan dengan serial processing, maka pada paralel processing dengan 2 core ini telah terjadi optimasi execution time. Pada jumlah centroid 10 , execution time pada parallel processing lebih cepat 24 milisecond atau 20\%. Tidak terjadi lonjakan nilai execution time yang signifikan, sehingga dapat disimpulkan bahwa sama halnya dengan lapply(), method mclapply() juga dijalankan secara konsisten.

TABEL IV

SKenARIO PARALLEL PROCESSING 3 CORE

\begin{tabular}{|l|c|c|c|c|c|c|}
\hline \multirow{2}{*}{$\mathbf{n}$} & \multicolumn{7}{|c|}{ Percobaan ke } & \multirow{2}{*}{ Mean } \\
\cline { 2 - 6 } & $\mathbf{1}$ & $\mathbf{2}$ & $\mathbf{3}$ & $\mathbf{4}$ & $\mathbf{5}$ & \\
\hline 10 & 0,096 & 0,092 & 0,092 & 0,095 & 0,091 & 0,093 \\
\hline 50 & 0,178 & 0,173 & 0,172 & 0,180 & 0,180 & 0,177 \\
\hline 100 & 0,257 & 0,261 & 0,260 & 0,259 & 0,258 & 0,259 \\
\hline 150 & 0,325 & 0,323 & 0,324 & 0,323 & 0,321 & 0,323 \\
\hline 200 & 0,369 & 0,374 & 0,377 & 0,371 & 0,381 & 0,374 \\
\hline 250 & 0,397 & 0,414 & 0,411 & 0,403 & 0,408 & 0,407 \\
\hline
\end{tabular}

Execution time pada parallel processing dengan 3 core secara umum lebih kecil daripada execution time dengan 2 core, namun perbedaannya tidak terlalu besar. Selisih terbesar antara 2 core dan 3 core dihasilkan pada jumlah centroid terbanyak yaitu 120 centroid. Sedangkan pada jumlah centroid terkecil selisih execution time hanya 2 milisecond. Dapat disimpulkan bahwa menambah jumlah core tidak selalu menghasilkan optimasi yang besar.

TABEL V

SKenario PARALLEL PROCESSING 4 CORE

\begin{tabular}{|c|c|c|c|c|c|c|}
\hline \multirow{2}{*}{$\mathbf{n}$} & \multicolumn{5}{|c|}{ Percobaan ke } & \multirow{2}{*}{ Mean } \\
\cline { 2 - 6 } & $\mathbf{1}$ & $\mathbf{2}$ & $\mathbf{3}$ & $\mathbf{4}$ & $\mathbf{5}$ & \\
\hline 10 & 0,085 & 0,085 & 0,088 & 0,078 & 0,082 & 0,084 \\
\hline 50 & 0,146 & 0,147 & 0,146 & 0,146 & 0,145 & 0,146 \\
\hline 100 & 0,209 & 0,210 & 0,209 & 0,208 & 0,214 & 0,210 \\
\hline 150 & 0,262 & 0,263 & 0,263 & 0,267 & 0,262 & 0,263 \\
\hline 200 & 0,368 & 0,306 & 0,308 & 0,299 & 0,302 & 0,317 \\
\hline 250 & 0,331 & 0,333 & 0,330 & 0,331 & 0,327 & 0,330 \\
\hline
\end{tabular}

Dapat dilihat pada Tabel V, bahwa execution time parallel processing dengan 4 core menghasilkan optimasi yang paling besar dibandingkan dengan jumlah core lainnya. Jika dibandingkan dengan 3 core maka dihasilkan optimasi paling besar sebanyak 73 milisecond yaitu pada jumlah centroid 250. Selanjutnya untuk analisis keseluruhan skenario, maka dibuat tabel dan grafik execution time tiap skenario dan tiap jumlah centroid. Tabel VI dan Gambar 5 merupakan perbandingan rata-rata execution time serial dan parallel processing untuk tiap jumlah centroid.

TABEL VI

PERBANDINGAN EXECUTION TIME

\begin{tabular}{|c|r|r|r|l|}
\hline \multirow{2}{*}{$\mathbf{n}$} & \multicolumn{4}{|c|}{ Jumlah Core } \\
\cline { 2 - 5 } & $\mathbf{1}$ (Serial) & $\mathbf{2}$ & $\mathbf{3}$ & $\mathbf{4}$ \\
\hline 10 & 0,119 & 0,095 & 0,093 & 0,084 \\
\hline 50 & 0,272 & 0,188 & 0,177 & 0,146 \\
\hline 100 & 0,424 & 0,270 & 0,259 & 0,210 \\
\hline 150 & 0,541 & 0,342 & 0,323 & 0,263 \\
\hline 200 & 0,635 & 0,396 & 0,374 & 0,317 \\
\hline 250 & 0,685 & 0,433 & 0,407 & 0,330 \\
\hline
\end{tabular}

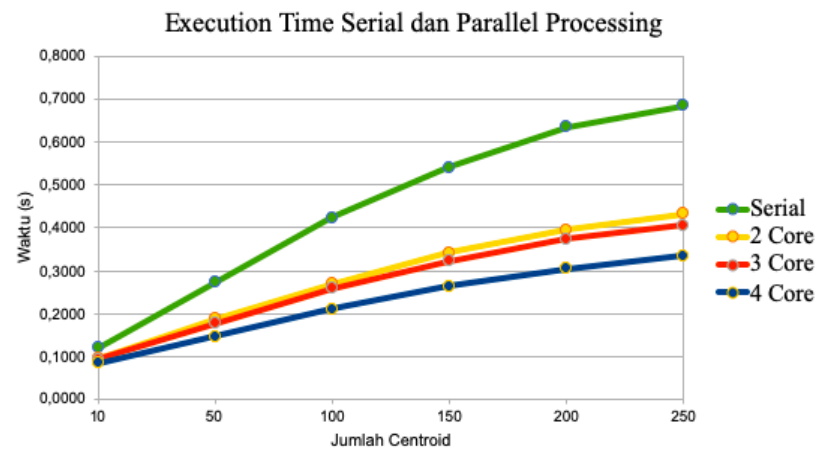

Gambar. 5 Grafik hasil pengujian serial dan parallel processing

Dengan menjadikan execution time pada serial processing sebagai dasar perbandingan, maka dapat dilakukan analisis optimasi. Pada jumlah centroid paling kecil, yaitu 10, optimasi execution time yang dihasilkan oleh parallel processing dengan 2 core adalah sebesar $20 \%$ Jika dijalankan dengan 4 core maka menghasilkan optimasi sebesar 29\%. Semakin tinggi jumlah centroid, maka optimasi yang dihasilkan juga semakin besar. Penurunan execution time terjadi secara signifikan mulai dari jumlah centroid 100 atau lebih. Pada jumlah centroid 100, optimasi yang dihasilkan jika menggunakan 4 core adalah $50 \%$. Optimasi tertinggi dihasilkan pada jumlah centroid terbesar, yaitu 250. Parallel processing pada jumlah centroid 250 menggunakan 4 core menghasilkan optimasi terbesar yaitu $52 \%$,

Jumlah centroid berpengaruh besar pada execution time. Semakin banyak jumlah centroid, maka semakin banyak waktu yang diperlukan untuk menjalankan algoritma KMeans. Hal ini disebabkan karena semakin banyak jumlah centroid, maka semakin banyak pula nilai jarak yang harus dihitung antar data dengan masing-masing centroid. Dari hasil pengujian, dapat dilihat bahwa execution time pada parallel processing untuk tiap kasus selalu lebih kecil daripada execution time pada serial processing. Dengan demikian maka dapat diambil kesimpulan bahwa implementasi strategi paralel berhasil melakukan optimasi dalam menjalankan algoritma K-Means.

\section{KESIMPULAN}

Pada penelitian ini telah dilakukan optimasi algoritma clustering K-Means dengan menjalankan algoritma tersebut secara paralel pada framework R. Untuk mengukur seberapa tinggi optimasi yang berhasil dilakukan, maka dilakukan perbandingan execution time antara serial processing menggunakan method lapply dan paralel processing menggunakan method mclapply. Dari hasil percobaan didapatkan bahwa parallel processing dengan jumlah core lebih dari 2 memperoleh execution time lebih kecil dari pada serial processing. Optimasi tertinggi didapatkan pada saat parallel processing dijalankan pada core yang paling banyak, yaitu 4 core. Dengan demikian dapat disimpulkan bahwa makin banyak jumlah core maka makin kecil execution time. 


\section{UCAPAN TERIMA KASIH / ACKNOWLEDGMENT}

Penelitian ini dibiayai oleh Universitas Sriwijaya pada Skema Hibah Sains Teknologi dan Seni tahun 2020.

\section{REFERENSI}

[1] B. Parhami, "Parallel Processing with Big Data," Encycl. Big Data Technol.,pp. 1-7, 2018.

[2] R. Harris, “An Introduction to R,” Quant. Geogr. Basics, vol. 2 , pp. 250-286, 2018

[3] P. Pacheco, An Introduction to Parallel Programming. 2011.

[4] G. Xie et al., "Minimizing redundancy to satisfy reliability requirement for a parallel application on heterogeneous serviceoriented systems," IEEE Trans. Serv. Comput., vol. 13, no. 5, pp. 871-886, 2020.

[5] P. Kasap and B. Şeyda, "The Review of Attributes Influencing Housing Prices using Data Mining Methods," vol. 4531, pp. $155-165$.

[6] A. Ali, "The Boston Housing Dataset Analysis University of Cumberlands," no. September, 2020

[7] M. Hittmeir, A. Ekelhart, and R. Mayer, "Utility and Privacy Assessments of Synthetic Data for Regression Tasks," Proc. 2019 IEEE Int. Conf. Big Data, Big Data 2019, pp. 5763-5772, 2019.

[8] N. Yusliani, R. Primartha, and M. Diana, "Multiprocessing Stemming: A Case Study of Indonesian Stemming," Int. J. Comput. Appl., vol. 182, no. 40, pp. 15-19, 2019.
[9] C. Ledur, D. Griebler, I. Manssour, and L. G. Fernandes, "A High-Level DSL for Geospatial Visualizations with Multi-core Parallelism Support," Proc. - Int. Comput. Softw. Appl. Conf., vol. 1, pp. 298-304, 2017.

[10] M. D. Marieska, M. R. P. Sufa, A. Widianto, N. Yusliani, and R. I. Heroza, "Performance Analysis of Parallel Processing on GPU for Simple Mathematical Computations," vol. 172, no. Siconian 2019, pp. 294-299, 2020.

[11] E. Mahdi, "A Survey of R Software for Parallel Computing," Am. J. Appl. Math. Stat., vol. 2, no. 4, pp. 224-230, 2014

[12] L. S. Riza, M. A. Ashari, and R. Megasari, "The Implementation of Gradient Descent Based Methods Using Parallel Computing in R for Regression Tasks," Proceeding - 2018 Int. Symp. Adv. Intell. Informatics Revolutionize Intell. Informatics Spectr. Humanit. SAIN 2018, pp. 37-42, 2019.

[13] M. Jones, "No Title," 2017.

[14] V. M. Steen and A. S. Tanenbaum, Distributed Systems, 3rd ed. 2017.

[15] M. Kalra, N. Lal, and S. Qamar, "K-Mean Clustering Algorithm Approach for Data Mining of Heterogeneous Data," Lect. Notes Networks Syst., vol. 10, no. January, pp. 61-70, 2018.

[16] Yudi Agusta, "K-Means - Penerapan, Permasalahan dan Metode Terkait," J. Sist. dan Inform., vol. 3, no. Februari, pp. 47-60, 2007

[17] H. Crc, Data Mining with R-Kumar. .

[18] R. September, "Package “parallel,"” pp. 1-14, 2020

[19] A. Brian, B. Venables, D. M. Bates, D. Firth, and M. B. Ripley, "Package 'MASS ,"' 2020. 